\title{
Effect of Recombinant Human Erythropoietin on Survivin Expression in Brain Tissues after Traumatic Brain Injury in Rats
}

\author{
Peng Lei, Longfeng Peng, Xingchao Zhang \\ Department of Neurosurgery, Lanzhou General Hospital, Lanzhou, China \\ Email: leipp2003@yahoo.com.cn
}

Received January 8, 2011; revised December 17, 2011; accepted January 3, 2012

\begin{abstract}
Objective: To explore the regulative effect on Survivin of r-HuEPO after traumatic brain injury (TBI) in rats, and understand the neuroprotection mechanisms of r-HuEPO. Methods: Seventy-eight adult Wistar rats were randomly divided into sham operation group $(\mathrm{n}=6)$, TBI group $(\mathrm{n}=36)$ and $\mathrm{r}$-HuEPO group $(\mathrm{n}=36)$. The experimental TBI model was created by Feeney's method. Samples were obtained after injury for measuring apoptosis of cells by Epics XL Flow Cytometer. Immunochemical method was performed for inspection of expressions of Survivin and NF- $\kappa$ B proteins. Results: Compared to the sham group, the number of apoptotic cells and Survivin, NF- $\kappa$ B immunopositive cells was significantly increased in the injured brain after TBI $(\mathrm{P}<0.01)$. R-HuEPO significantly increased the expression of survivin and NF- $\kappa \mathrm{B}$, but decreased the apoptotic rates. Conclusion: Increased expression of NF- $\kappa \mathrm{B}$ by $\mathrm{r}-\mathrm{HuEPO}$ may play important role in regulating Survivin level, inhibiting neuronal apoptosis in cortex and exerting protective function to neurons.
\end{abstract}

Keywords: Recombinant Human Erythropoietin (r-HuEPO); Brain Injury; Survivin; NF- $\kappa$ B; Apoptosis

\section{Introduction}

Survivin was one of the new-found genes of the apoptosis inhibitor family. The protein expression of Survivin increased significantly after traumatic brain injury (TBI), nevertheless, it does not express in normal differentiated mature tissue. Recombinant human erythropoietin ( $\mathrm{r}-\mathrm{Hu}-$ EPO) has neuroprotective effect after traumatic brain injury (TBI), however, the specific mechanism of it was still unclear [1,2]. This study is to explore the effect of $r-$ HuEPO on NF- $\kappa$ B, Survivin and cell apoptosis after TBI in rat, in the mean time, illuminate the potential mechanism of neuroprotective effect of r-HuEPO.

\section{Materials and Methods}

\subsection{Main Instruments and Reagents}

Epics XL flow cytometer (United States Becman-Coulter), BI-2000 image analysis system (Cheng du Tai meng Technology Co., Ltd.), r-HuEPO (Bei Jing Fourth Ring biopharmaceutical Ltd., Lot \# S20020045), NF- $\kappa$ B P65 monoclonal antibody, Survivin polyclonal antibody. Santa Cruz Products, SP Kit and the DAB reagent (purchased from the box in the Shan Jin Qiao Biotechnology Limited in Beijing).

\subsection{Experimental Animal and Groups}

Healthy male Wistar rats, SPF, weight $(260 \pm 20) \mathrm{g}$, (Provided by Faculty of Medicine Centre for Experimental Animals, Gansu provinces, as SCXK (GAN) 2004-007). Animals were randomly divided into sham-operated control group, brain injury group and r-HuEPO treatment group, which administrated with intraperitoneal injection of r-HuEPO (3000 IU/kg) after TBI.

The doses of recombinant human EPO administered in the majority of the animal studies cited are generally in the range of $1000-5000 \mathrm{U} / \mathrm{kg}$, which is over 10 times higher than those currently used clinically in anemic patients with chronic renal failure [13]. In the sham-operated group collected samples one day after injury, other groups were collected samples more than 6 hour and 1, 2, 3, 5, 7 days after injury respectively. Six rats were used at each of the time points.

\subsection{Animal Model Method}

The experimental TBI model was created by Feeney's method [3]. Anesthesia was performed with sodium pentobarbital $(60 \mathrm{mg} / \mathrm{kg})$ by intraperitoneal injection. The head was fixed in stereotactic apparatus along the midline incision scalp, periosteal stripping exposed to the 
right parietal bone. The born window of $5 \mathrm{~mm}$ in diameter was created by using dental drilling in the site of 1.5 $\mathrm{mm}$ behind the coronal slit and $2.5 \mathrm{~mm}$ beside the midline and the dural matter integrity was kept to. A weight of 40 grams fell freely to hit and make contusion of the right parietal lobe. Then the bone window was closed with the bone wax and scalp incition sutured. According to the sub-time points after injury, the animals were decapitated. In addition to sham-operated group is not against, other steps was the same. In r-HuEPO treatment groups, intraperitoneal injection of r-HuEPO $(3000 \mathrm{IU} / \mathrm{kg}$, referenced from clinical administration) was administrated immediately after TBI.

\subsection{Immunohistochemical Detection}

Expression of Survivin and NF- $\kappa$ B was detected for study, measured with digital image analysis. Injured brain tissue with a complete cortex was selected, and was sliced along the coronal continually with thickness of $10 \mathrm{um}$ after embedding in paraffin conventionally. Observation of Survivin and NF- $\kappa$ B immune response was conducted with optical microscopy, and used BI-2000 image analysis system for quantitative image analysis. Optical density (OD) was used to evaluate Survivin and NF- $\kappa \mathrm{B}$ immunohistochemical staining intensity, and compared to the group OD value. We measured the optical density of each immunopositive cell using BI-2000 to calculate a numeration of each candidate genes' expression, where optical density representing immunopositive cells.

\subsection{Measure Neuronal Apoptosis}

The fresh injured brain tissue of 100-150 mg was selected, in PBS solution homogenated, tissue homogenated liquid was filtered with 400 holes screen, filtrate was located in centrifuge tube, treated by $1000 \mathrm{r} / \mathrm{min}$ for $5 \mathrm{~min}$, washed twice with PBS , 70\% ethanol-fixed, left on the condition of $4^{\circ} \mathrm{C}$. Centrifugal supernatant to the next day, washed once with PBS, $1 \mathrm{ml}$ PI dye was plused (concentration of $50 \mu \mathrm{g} / \mathrm{ml}, 32.4 \mathrm{ml}$ of normal saline, PI2.5 mg, Rnase $0.5 \mathrm{mg}$, Triton X-100-0.25 ml, $50 \mathrm{mg}$ sodium citrate, and distilled water to $50 \mathrm{ml}$ ), At $4{ }^{\circ} \mathrm{C}$ the dark stain was performed for $30 \mathrm{~min}$. Epics XL application of flow cytometry record argon plasma excitation wavelength of $488 \mathrm{~nm}$ and red fluorescence, count 10,000 samples each cell to cell apoptosis detection indicators as a percentage.

\subsection{Statistics}

SPSS10.0 statistical software was used for analysis and the data described with $\mathrm{X} \pm \mathrm{S}$. One-way ANOVA groups were compared using the least significant difference method for every $2, \mathrm{P}<0.05$ for statistical significance.

\section{Results}

\subsection{Changes in the Rates of Neuronal Apoptosis}

In all brain injured group the neuronal apoptosis rates were higher than the sham-operated group, reached the peak 2 days after injury, then gradually declined. But the rates still were high until 7 days after injury $(\mathrm{P}<0.01)$. The rates in $\mathrm{r}-\mathrm{HuEPO}$ treatment group, except for the time points within 6 hours and 7 days after injury, were significantly lower than the control group $(\mathrm{P}<0.05)$ (see Table 1).

The apoptosis rates of TBI group and r-HuEPO treatment group were significantly higher than samples obtained from sham-operation group. * shows statistic analysis acquires $\mathrm{P}<0.01$ TBI group compare with sham-operation. However, r-HuEPO group expressed a significant different in apoptosis rate, compare with TBI group, which labeled by $\Delta$.

\subsection{Expression of Survivin Protein and NF- $\kappa$ B in the Different Groups}

Survivin and NF- $\kappa$ B positive staining positioning in the cytoplasm and (or) membrane showed yellow color (see Figures 1 and 2). A small amount of expression of Survivin was observed 3 days after traumatic brain injury, reached at the peak at $7 \mathrm{~d}$ after traumatic brain injury. Both TBI group and r-HuEPO group samples expressed Survivin at $3 \mathrm{~d}, 5 \mathrm{~d}, 7 \mathrm{~d}$, which indicated significantly $(\mathrm{P}<$ $0.01)$, compare to the sham-operation group. Expression of Survivin could be observed 1d after injury in r-HuEPO treatment group, reached peak at $5 \mathrm{~d}$, Compared with the brain injury groups $1 \mathrm{~d}, 2 \mathrm{~d}, 3 \mathrm{~d}, 5 \mathrm{~d}$ after injury, Survivin expression was significantly increased $(\mathrm{P}<0.01)$ (see Figure 3). NF- $\kappa \mathrm{B}$ was obviously expressed $6 \mathrm{~h}$ after injury, peaked at $1 \mathrm{~d}$, then decreased gradually, also was significantly higher than that of sham-operated group after $7 \mathrm{~d}(\mathrm{P}<0.01)$; NF- $\kappa \mathrm{B}$ of brain injury in $\mathrm{r}-\mathrm{HuEPO}$ treatment group at each time point expressed higher significantly than brain injury groups $(\mathrm{P}<0.05)$ (see Figure 4).

Table 1. Apoptosis rates of injured brain of different groups (\%).

\begin{tabular}{|c|c|c|c|c|c|c|}
\hline \multirow{2}{*}{ Groups } & \multicolumn{6}{|c|}{ Apoptosis rates $(\%)$} \\
\hline & $6 \mathrm{~h}$ & $1 d$ & $2 \mathrm{~d}$ & $3 d$ & $5 d$ & $7 \mathrm{~d}$ \\
\hline Sham-operation & $2.06 \pm 0.53$ & & & & & \\
\hline TBI & $10.96 \pm 1.24 *$ & $15.90 \pm 1.41^{*}$ & $22.76 \pm 1.86^{*}$ & $17.12 \pm 1.51^{*}$ & $16.42 \pm 1.07 *$ & $14.48 \pm 0.54^{*}$ \\
\hline r-HuEPO & $9.46 \pm 1.30$ & $13.00 \pm 0.73 \Delta$ & $19.14 \pm 0.88 \Delta$ & $14.78 \pm 0.83 \Delta$ & $12.78 \pm 0.79 \Delta$ & $12.34 \pm 1.22$ \\
\hline
\end{tabular}



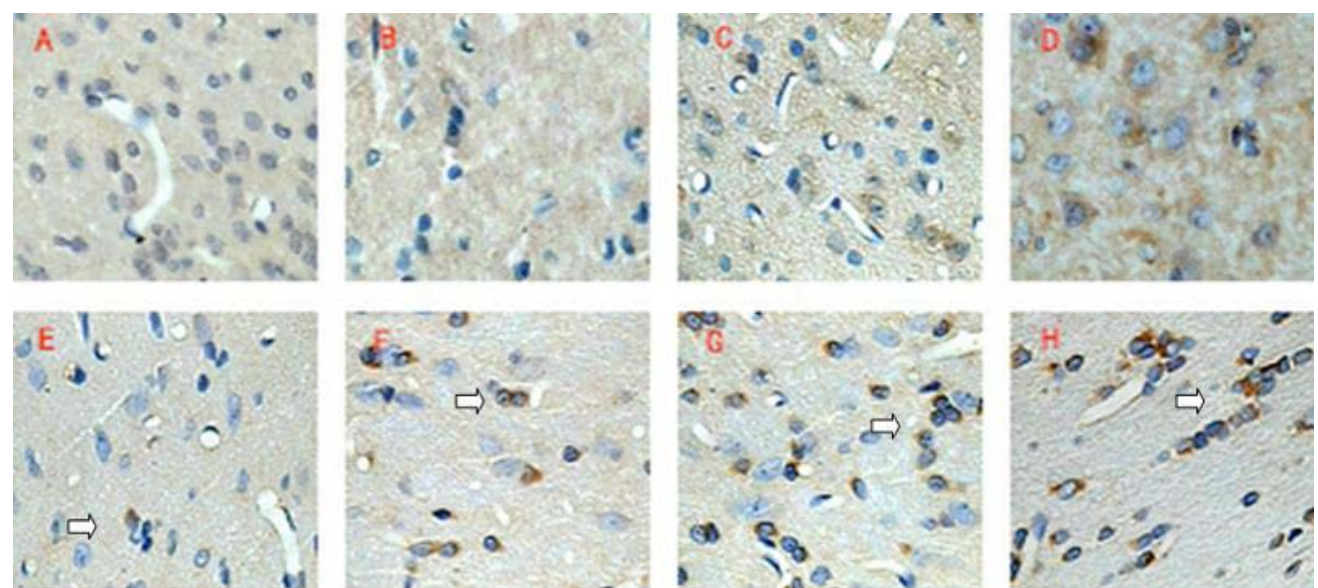

Figure 1. Immunohistochemical staining images provide the evidence of the expression of Survivin. Picture A, B, C, D shows Survivin proteins expressed (arrows) in the $1^{\text {st }}, 3^{\text {rd }}, 5^{\text {th }}, 7^{\text {th }}$ day after TBI of samples from TBI group. Picture E, F, G and $H$ illustrate the Survivin expression (arrows) at same time point, which obtained from samples of r-HuEPO group, which revealing r-HuEPO may induct the expression of Survivin.
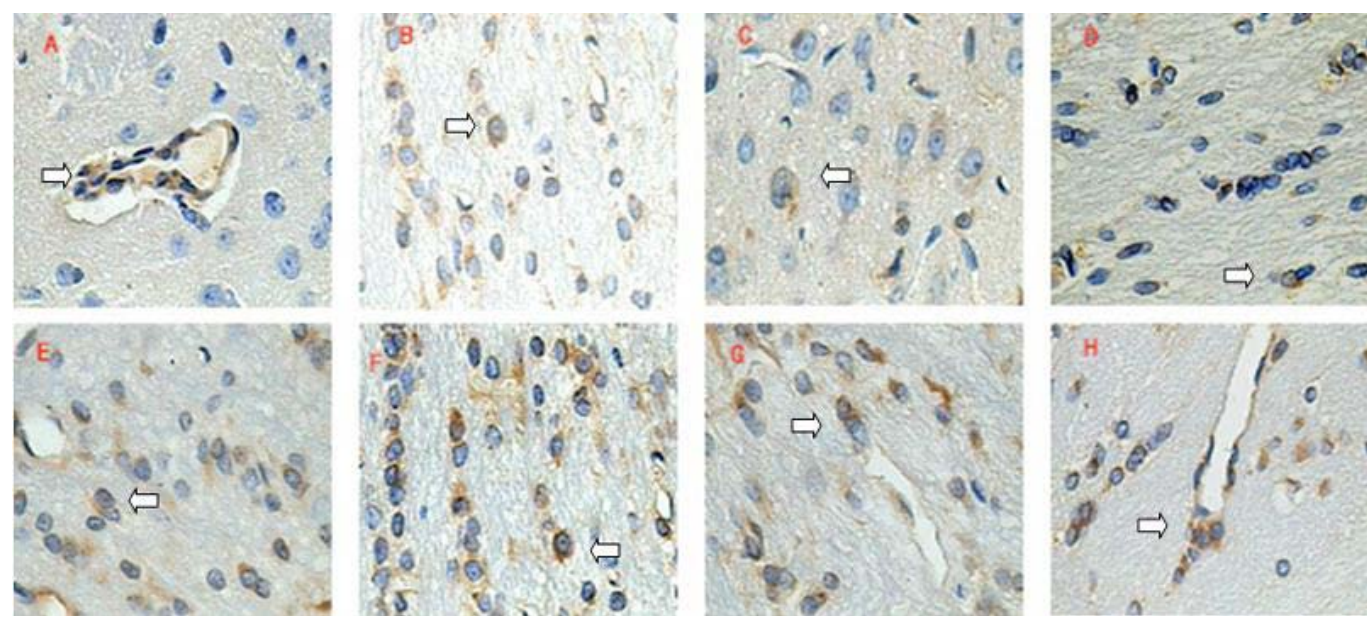

Figure 2. Expression of NF- $\kappa$ B protein in the different groups, illustrated via immunohistochemical staining. Image A, B, C and $D$ refers to the expression of NF- $\kappa B$ at the $6 \mathrm{~h}, 3^{\text {rd }}, 5^{\text {th }}$ and $7^{\text {th }}$ day after TBI (arrows) (E-H). Section E, F, G and H expressed the observation of same time-point with TBI samples which administrated with r-HuEPO (arrows).

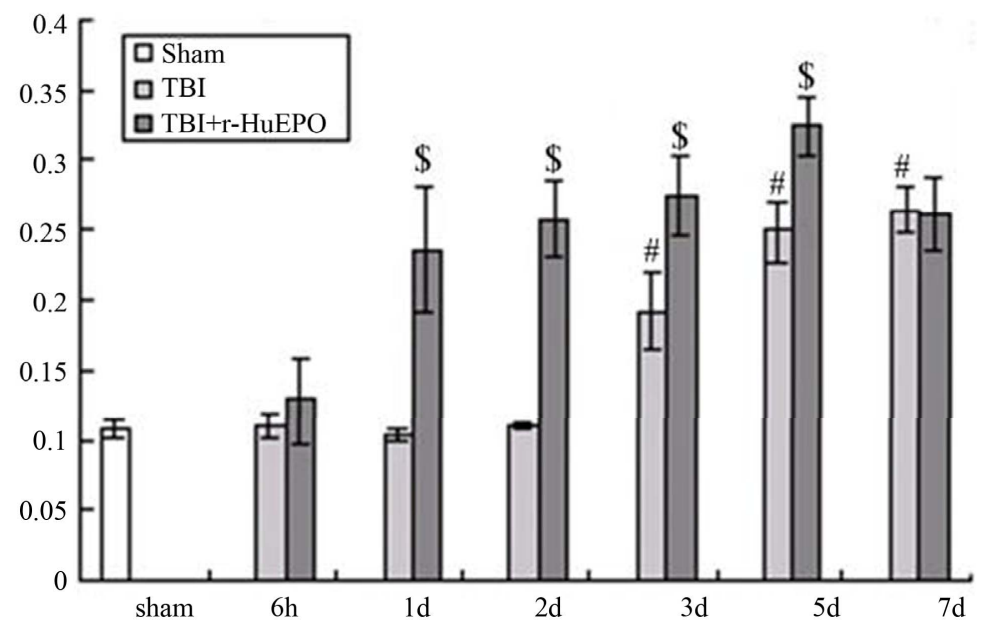

Figure 3. The effect of $\mathbf{r}-\mathrm{HuEPO}$ on expression of Survivin protein at different time points after TBI in rats (Note: $* \mathbf{P}>0.05$, vs sham group: \#P < 0.01, vs sham group; $\$$ P < 0.01, vs TBI group; @ > 0.05, vs TBI group). 


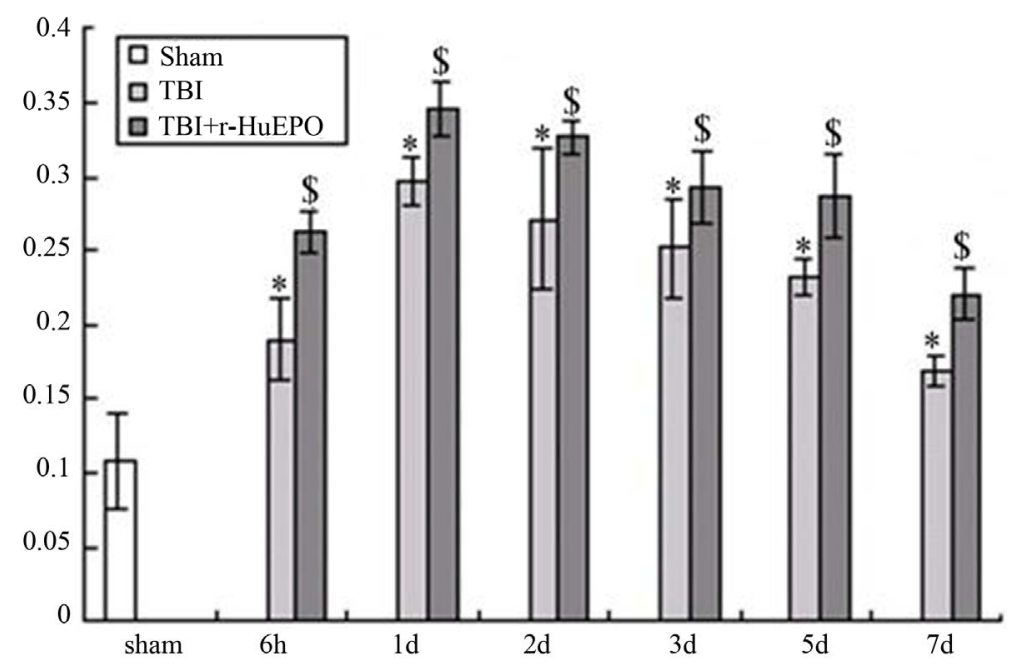

Figure 4. The effect of r-HuEPO on expression of NF- $\kappa$ B at different time points after TBI in rats (Note: $* P<0.010 .05$, vs sham group: \#P < 0.01, vs sham group; $\$ P<0.05$, vs brain injuried group).

\section{Discussion}

Traumatic brain injury is one of the common clinical fatal diseases and very harmful to human health $[4,5]$, and its pathophysiological mechanism is very complicated. Recent studies has given the evidence that the neural cell apoptosis occurred in head injury can promote the secondary brain damage, therefore lead to poor prognosis of the patients [6]. Consequently, the anti-neuronal apoptosis is supposed to be as an important aspect of severe head injury treatment.

Many studies results confirmed that EPO is endogenous cytokines of the central nervous system, and play a neurotrophic and neuroprotective role through neurons and glial cells paracrine effecting on neuron EPO-R. Outside endogenous EPO in a condition of the brain injury can struggle against neuronal apoptosis through penetrating the brain blood barrier and protect the brain from damage [7,8]. Yatsiv, etc. [2] reported that EPO reduced apoptosis and inflammatory response significantly in rat closed brain injury, promoted the restoration of cognitive and move function. Kumral, etc. [9] study found that EPO could reduce apoptosis through inhibiting pro-apoptotic gene expression of bax and DP5, plays a role in protection of the brain. But both home and abroad reported rarely about whether EPO can increase the expression of Survivin neuroprotective. Author explored the mechanism of EPO through the observation the effect of r-HuEPO on nerve cells' expression of Survivin and NF- $\kappa \mathrm{B}$ after traumatic brain injury, provide evidence for clinical application.

Survivin is a new member of inhibitors of apoptosis protein family; it is isolated from the human genome library by effector cell protease receptor-1 cDNA and hybridization screening. It locates on the chromosome 17q25, which contains 142 amino acids. Survivin is not expressed in the normal differentiation of mature tissues. However, it has the high expression in most tumor tissues and after brain injury. Survivin plays the role of cell cycle regulation and anti-apoptotic $[1,10]$. NF- $\kappa \mathrm{B}$ signal transduction pathways is an important signal control system that involved in cell apoptosis, its increase can promote massive anti-Apoptosis factor expression in brain, and participate in gene encoding the transcription of inflammatory molecules after brain injury [11].

This study found that Survivin expression appeared early in the brain after injury in the treatment group with $\mathrm{r}-\mathrm{HuEPO}$, and its peak of the expression was earlier than in the control group. Compared to the control group, 1d, $2 \mathrm{~d}, 3 \mathrm{~d}, 5 \mathrm{~d}$ after injury, Survivin expression levels were significantly increased, and apoptosis rates was significantly decreased. In injury brain side at each time point, $\mathrm{NF}-\kappa \mathrm{B}$ expression were significantly increased in the treatment group with $\mathrm{r}-\mathrm{HuEPO}$ than the control group, and kept continuing high level.

Previous work shows that binding of Epo to its receptor, the receptor forms homodimers and undergoes phosphorylation by physically associating and interacting with the tyrosine kinase JAK2 (Janus Kinase-2). Siren also showed that Epo activates JAK2 cascades which activate $\mathrm{NF}-\kappa \mathrm{B}$ [14]. Therefore, the EPO administration causes the nuclear translocation of $\mathrm{NF}-\kappa \mathrm{B}$. This study consist with the previous and in addition, expands the pathway that the translocation of $\mathrm{NF}-\kappa \mathrm{B}$ and the increasing in $\mathrm{NF}-\kappa \mathrm{B}$ association with DNA raise up of the synthesis and secretion of the anti-apoptotic factor (Survivin), thereby blocking the process of cell apoptosis, playing a brain Protective role. However, activation of NF- $\kappa \mathrm{B}$ can also promote the expression of pro-inflam-matory cytokines, promote inflammation process after brain injury, thereby increasing secondary brain damage after the brain injury [12]. On the other hand, r-HuEPO also plays 
an important role in suppression of Caspase-3 expression. Author's previous study indicates that Caspase- 3 expressed within 6 hours of TBI, which directly mediates one of important pathway of neuroapoptosis, however r-HuEPO administration may significiatly lower down the level of the Caspase-3 activation [15]. In the mean time, current understanding of r-HuEPO reveals it has strong relationship with variety of pro-inflammatory cytokines. Thereby, further research of $\mathrm{r}-\mathrm{HuEPO}$ in the mechanism of which regulates and controls the pathway in apoptosis and antiapoptosis will be necessary, to maximize the beneficial role in curing brain injury need further studies.

\section{REFERENCES}

[1] E. A. Johnson, S. I. Svetlov, K. K. Wang, et al., "Cell-Specific DNA Fragmentation May Be Attenuated by a Survivin-Dependentmechanism after Traumatic Brain Injury in Rats," Experimental Brain Research, Vol. 167, No. 1, 2005, pp. 17-26. doi:10.1007/s00221-005-2362-2

[2] I. Yatsiv, N. Grigoriadis, C. Simeonidou, et al., "Erythropoietinis Neuroprotective, Improves Functional Recovery, and Reducesneuronal Apoptosis and Inflammation in a Rodent Modelof Experimental Closed Head Injury," FASEB Journal, Vol. 19, No. 12, 2005, pp. 1701-1703.

[3] J. Y. Jiang and C. Z. Luo, "Modern Brain Injury," The Second Military Medical University, Shanghai, 2004, pp. 417419.

[4] P. Lei, L. Z. Tian, Y. Wang, et al., "General Treatment for Severe Brain Injury," Chinese Journal of Trauma, Vol. 21, No. 7, 2005, pp. 541-543.

[5] P. Lei, "Master the Key Points in Treatment of Severe Traumatic Brain Injury," Magazine Trauma Surgery, Vol. 8, No. 5, 2006, pp. 385-387.

[6] P. G. Marciano, J. Brettschneider, E. Manduchi, et al., "Neuron-Specific mRNA Complexity Responses during HippoCampal Apoptosis after Traumatic Brain Injury," Journal of Neuroscience, Vol. 24, No. 12, 2004, pp. 2866-2876. doi:10.1523/JNEUROSCI.5051-03.2004

[7] M. Hasselblatt, H. Ehrenreich and A. L. Siren, "The Brain Erythropoietinsystem and Its Potential for Therapeutic Exploitationin Brain Disease," Journal of Neurosurgical
Anesthesiology, Vol. 18, No. 2, 2006, pp. 132-138. doi:10.1097/00008506-200604000-00007

[8] H.-T. Lan and Q. J. Zhang, "Recombinant Human Erythropoietin on Focal Cerebral Ischemia-Reperfusion Injury Inflammation of the Protective Effect of r-HuEPO on InflameMatory Injury Induced by Focal Cerebral Ischamia/Reperfusion in Rats," Chinese Neurosurgery, Vol. 22, No. 1, 2006, pp. 51- 54.

[9] A. Kumral, S. Genc, E. Ozer, et al., "Erythropoietin Downregulatesbax and DP5 proapoptotic Gene Expression in Neonatalhypoxic-Ischemic Brain Injury," Biology of the Neonate, Vol. 89, No. 3, 2006, pp. 205-210. doi:10.1159/000089951

[10] W. J. van Houdt, Y. S. Haviv, B. Lu, et al., "The Human Survivinpromoter: A Novel Transcriptional Targeting Strategy Fortreatment of Glioma," Journal of Neurosurgery, Vol. 104, No. 4, 2006, pp. 583-592. doi:10.3171/jns.2006.104.4.583

[11] P. Sompol, Y. Xu, W. Ittarat, et al., "NF- $\kappa$ B-Associated MnSOD Induction Protects against $\beta$-Amyloid-Induced Neuronal Apoptosis," Journal of Molecular Neuroscience, Vol. 29, No. 3, 2006, pp. 279-288. doi:10.1385/JMN:29:3:279

[12] A. J. Williams, J. R. Dave and F. C. Tortella, "Neuroprotection with the Proteasome Inhibitor MLN519 in Focal Ischemic Brain Injury: Relation to Nuclear Factor $\kappa \mathrm{B}$ $(\mathrm{NF}-\kappa \mathrm{B})$, Inflammatory Gene Expression, and Leukocyte Infiltration," Neurochemistry International, Vol. 49, No. 2, 2006, pp. 106-112. doi:10.1016/j.neuint.2006.03.018

[13] National Kidney Foundation-Dialysis Outcomes Quality Initiative, "NKF-DOQI Clinical Practice Guidelines for the Treatment of Anemia of Chronic Renal Failure," American Journal of Kidney Diseases, Vol. 30, Suppl. 3, 1997, pp. S192-S240.

[14] A.-L. Siren, et al., "Erythropoietin Prevents Neuronal Apoptosis after Cerebral Ischemia and Metabolic Stress," Proceedings of the National Academy of Sciences, Vol. 98, No. 7, 2001, pp. 4044-4049. doi:10.1073/pnas.051606598

[15] P. Lei, et al., "Protective Role of Erythropoietin for Traumatic Brain Injury with Shock in Rats," Chinese Journal of Neurosurgery, Vol. 24, No. 7, 2008, pp. 553-555. 